\title{
ВИЧ В ТРАНС*ПОПУЛЯЦИИ: LOCAL CASE STUDY
}

\author{
ЯЭЛЬ ДЕМЕДЕЦКАЯ, БОРИС ДЕНИСОВ, АЛИСА ЛАПИЦКАЯ
}

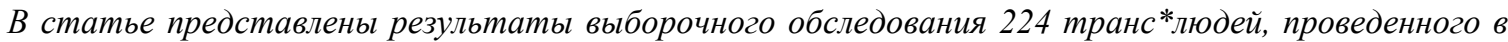
2017 2. группой Gender Dynamics Research (GDR). Обследование выявило высокую степень поражённости группы. Кроме этого выявлень очень низкий уровень информированности о ВИЧ-инфекиии и способах её распространения. Источники знаний о ВИЧ более или менее стандартны. Отношение $\kappa$ факту инфицирования и возможного инфицирования можно охарактеризовать как безразличное или неадекватное, что, по всей вероятности, предопределено жёсткой стигматизацией группы и высоким уровнем испытываемой дискриминации. Отмечено, что государство не справляется с распространением ВИЧ-инфекиии.

Ключевые слова: транс*, трансгендер, ЛГБТ, ВИЧ/СПИД, ВИЧ-инфекиия, выборочное обследование.

\section{ВВЕДЕНИЕ}

По оценкам ЮНЭЙДС, эпидемия ВИЧ в России продолжает развиваться быстрыми темпами, немного уступая только эпидемии в Африке к югу от Сахары (UNAIDS 2017). Отечественная статистика не противоречит этой оценке, хотя в официальных данных пропала однозначность. Теперь в нашей стране два официальных источника: Роспотребнадзор (старый, издаёт бюллетень ВИЧ, уже вышло 42 номера $^{1}$, последний выпуск датирован 2018 г., на сайте пока не представлен) и Минздрав (новый, публикуется онлайн ${ }^{2}$ ). ЮНЭЙДС оценивает размеры эпидемии на основе оценки размеров ключевых (в старой терминологии - уязвимых) групп ${ }^{3}$, данные о численности самих групп получаются из стран самыми разными способами. Таким образом, источники данных по ВИЧ-инфекции в нашей стране усложнились, монополия Федерального центра по профилактике и борьбе со СПИДом (ФНМЦ) ушла в прошлое. Число ВИЧинфицированных публикуют два разных источника, и оба являются официальными, а оценки ЮНЭЙДС перестали казаться сильно завышенными. Тем не менее в характеристиках тяжести эпидемии они сходятся, хотя по числу инфицированных есть разногласия.

ЯЭЛЬ АЛЕКСАНДРОВНА ДЕМЕДЕЦКАЯ (yaelkroy@gmail.com), ФОНД ТРАНСГЕНДЕР, РОССИЯ.

БоРИС ПЕТРОвИч ДЕНИСов (denisov@demography.ru), ИсСЛЕДОВАНИЯ ГЕНДЕРНОЙ ДИНАМИКИ, РосСия.

АЛИСА ВАЛЕРЬЕВНА ЛАПИЦКАЯ (lapitskaya.alisa@gmail.com), ИССЛЕДОВАНИЯ ГЕНДЕРНОЙ ДИНАМИКИ, РосСия.

СТАТЬЯ ПОСТУПИЛА В РЕДАКЦИЮ В ФЕВРАЛЕ 2019 Г.

\footnotetext{
${ }^{1}$ URL: http://www.hivrussia.ru/stat/bulletin.shtml\#40 (дата обращения: 25.09.2018).

${ }^{2}$ URL: http://hivorg.mednet.ru/open/statistika.php (дата обращения: 25.09.2018).

${ }^{3}$ Ключевые группы населения - это группы лиц, подвергающихся повышенному риску инфицирования ВИЧ, независимо от типа эпидемии или местных условий. К таким группам относятся: мужчины, имеющие секс с мужчинами; лица, употребляющие инъекционные наркотики; лица, находящиеся в местах лишения свободы и других условиях изолированного пребывания; секс-работники и их клиенты, а также трансгендерные лица (BO3, URL: http://www.who.int/ru/news-room/fact-sheets/detail/hiv-aids) (дата обращения: 25.09.2018).
} 
Одной из ключевых групп являются трансгендерные люди, или транс*люди 4 . Это относительно новая ключевая группа, ещё совсем недавно о ней знали, только обращая внимание на последнюю букву в аббревиатуре ЛГБТ ${ }^{5}$ Транс*люди - это зонтичный термин, включающий в себя как тех, кто готов на гендерный переход (гормонотерапия и/или хирургические вмешательства), так и тех, для кого перемена биологического пола или его социального восприятия не является ключевой. Часть из них не идентифицирует себя с полом, данным при рождении, но при этом не причисляет себя к противоположному, такие транс*люди относятся к небинарным (non-binary). Не для всех таких поведений/стилей/гендерных дисплеев есть русские названия, например, gender bender, gender queer, gender fluid, drag queen и так далее не имеют аналогов в русском языке, но есть почти русское слово и даже амплуа «травести». Транс*люди - люди, которых не устраивает навязываемая социумом гендерная роль. Все эти группы объединены одним качеством, они практически не наблюдаемы (в частности, из-за трудности определения), в настоящее время в РФ для их изучения применяются главным образом качественные методы, возможно, исключая геев (мужчин-гомосексуалистов), о которых научная литература на русском языке всё-таки есть (на других языках довольно много).

Как уже говорилось, в России транс*люди не являются видимой частью общества, численность их неизвестна, никакой статистики практически нет ${ }^{6}$. Фрагментарные данные и разрозненные факты говорят о том, что трансгендерные люди, во-первых, существуют, и в России они есть, во-вторых, проблем у них больше, чем у «обычных» людей (Менделевич 2018), в-третьих, они занимают одно из заметных мест в распространении ВИЧ-эпидемии. Поэтому очень важно проводить направленные исследования ${ }^{7}$, позволяющие понять, чем и как живут эти люди. В предлагаемой работе делается попытка оценить некоторые количественные характеристики популяции и сделать рекомендации по ослаблению негативного влияния на неё эпидемии ВИЧ. В числе прочего мы попытались выяснить, насколько транс*люди информированы о проблеме ВИЧ, откуда они получают информацию, знают ли они свой ВИЧ-статус и, если он положительный, принимают ли терапию.

Имея в виду рост доли половой передачи ВИЧ (ВИЧ-инфекция 2018) ${ }^{8}$, следует отдельно ставить вопрос и изучать не только распространение инфекции среди так называемых сексуальных меньшинств и транс*людей, но и особенности их половой жизни. В Российской Федерации транс* люди (и все остальные тоже) не определяются по своей

\footnotetext{
${ }^{4}$ Далее используется термин транс* как более распространённый и считающийся политкорректным в транс* сообществе.

${ }^{5}$ Сама аббревиатура тоже имеет тенденцию к удлинению: ЛГБТК, ЛГБТКИ, но мы будем использовать вариант с четырьмя литерами.

${ }^{6}$ В этом смысле Россия принадлежит к огромному глобальному большинству. Страны, обладающие какойлибо статистикой, можно пересчитать по пальцам одной руки.

${ }^{7}$ О месте транс* исследований в дисциплинарной и факультетской системах знания см. (Keegan 2018).

Автор, в частности, настаивает на несводимости транс*исследований к квир-теории и академическому феминизму.

${ }^{8}$ Около половины от установленных новых случаев пути передачи вируса.
} 
идентификации, а только по биологическому полу ${ }^{9}$. Это порождает ограничения в общении и принятии их обществом. Возможность создать пару и найти свое место в жизни существует, но число возможных партнёров определяется весьма небольшим количеством очень толерантных людей, которые готовы построить пару и жить с транс*человеком. Из-за исторически сложившейся в России культуры отношения к меньшинствам в целом и к транс*людям, в частности, они стали и становятся более закрытыми и асоциальными, что усложняет изучение их специфики.

\section{ДАННЫЕ И МЕТОДЫ}

Исследовательская группа ГДР (Gender Dynamics Research, GDR или Исследования гендерной динамики ${ }^{10}$ ) была создана на рубеже 2015-2016 гг. на основе привлечения московским фондом «Трансгендер» ${ }^{11}$ исследователей МГУ и ВШЭ к работе по проблемам транс* людей. Непосредственным толчком начала исследований послужило намерение одной из студенток англоязычной магистерской программы НИУ-ВШЭ «Population and Development» подготовить доклад о трансгендерных людях в курсе «Family Planning», читавшемся приглашённым преподавателем из МГУ. Около двух лет назад было проведено небольшое исследование, результаты которого были доложены не только в рамках упомянутого курса ВШЭ, но и на конференциях (X Всероссийская научная конференция памяти Ю. Левады «Современное российское общество и социология» и V Международная конференция по ВИЧ/СПИДу в странах Восточной Европы и Центральной Азии). Проведённое исследование, в частности, показало, что степень заражения ВИЧ среди трансгендеров была очень высока (Демедецкая, Денисов, Сакевич 2017). В дальнейшем эта работа была продолжена.

В течение месяца в 2017 г. было проведено 264 телефонных интервью, из которых 224 оказались пригодны для использования и были обработаны. Выборка, как и прежде, была сделана из регистрационных карточек клиники РХАС (Медицинский центр реконструктивной хирургии андрологии и сексологии ${ }^{12}$ ), осуществляющей, в частности, операции по коррекции пола. У клиники и фонда давние связи, многие пациенты клиники активно участвуют в группах поддержки и других мероприятиях, проводимых фондом. В частности, фонд оказывает разнообразную поддержку как комиссии, определяющей возможность операции по коррекции пола, так и лицам, желающим его переменить. Транс*люди шли на контакт и отвечали на вопросы, потому что между исследовательской группой и трансгендерным сообществом давно установлены доверительные отношения. Также располагал к откровенности и тот факт, что телефонное интервью проводилось в рамках подхода «равный равному», т. е. транс*персоной.

\footnotetext{
${ }^{9}$ Справедливости ради заметим, что пол (гендер), отличный от мужского и женского, может быть документирован только в считанном числе стран (Индия, Канада, Австралия, некоторые штаты США), см. (Byrne 2014).

${ }^{10}$ URL: www.transgender.team (дата обращения: 30.01.2019).

${ }^{11}$ URL: www.transgender.ru (дата обращения: 30.01.2019).

12 URL: www.tmedi.ru (дата обращения: 30.01.2019).
} 
В настоящее время мы не можем оценить степень репрезентативности нашей выборки. Тем не менее некоторые качественные соображения по поводу репрезентативности есть. В списках пациентов клиники на момент обследования было около пяти с лишним тысяч записей, клиника действует с 2011 г. Это ведущая в нашей стране клиника, по числу операций она в разы превосходит аналогичную клинику в Санкт-Петербурге. О существовании других клиник практически ничего не известно, но их популярность и даже наличие маловероятны ${ }^{13}$. Все желающие изменить биологический пол, приписанный от рождения, концентрируются в Москве и Санкт-Петербурге. Это наблюдение построено на опыте out reach работы с ключевыми группами, из которой известно, что ЛГБТ более склонны к концентрации в крупных городах, а потребители психоактивных веществ более дисперсны. Мы предполагаем, что с течением времени спрос на операции по коррекции пола будет расти и клиники в других городах начнут проводить такие операции.

Отметим, что транс*население численно невелико, его доля в общем населении мала. При вероятностной процедуре выборки транс*люди в неё могут не попасть. В проведенное CDC (Centers for Disease Control and Prevention) в 2014 г. обследование в 31 штате и 1 территории США с выборкой более полумиллиона человек ${ }^{14}$ попало более 2 тыс. транс* людей, т. е. транс* преваленс составил 4\%о. От транс*людей около половины составили mtf, 30\% - ftm и 20\% - небинарные (gender nonconforming) люди (Lagos 2018). При изучении проблем транс*людей и других редких явлений, как правило, используются неслучайные выборки меньшего размера (Исаев 2016; Демедецкая, Денисов, Сакевич 2017; Русанова 2008; Nicolazzo 2016).

Транс*население практически не наблюдаемо, но теоретически можно предположить возможность статистического наблюдения в четырёх точках, где происходит контакт общества и транс*человека: 1) в комиссии, дающей разрешение на изменение пола; 2) в клинике, где происходит оперативное вмешательство; 3) в системе МВД, где происходит замена паспорта (основного документа); 4) в пенсионном фонде при внесении изменений в запись страхового номера индивидуального лицевого счёта (СНИЛС; рисунок 1), карточка СНИЛС является единственным документом, где перемена пола непосредственно упоминалась (до 2016 г.) ${ }^{15}$.

\footnotetext{
${ }^{13}$ Несмотря на то, что первая операция по хирургической коррекции пола (FTM) в СССР была проведена В. Калнберзсом (Viktors Kalnbērzs) в 1972 г. Минздрав СССР осудил операцию, запретил публикации о ней и проведение подобных операций в будущем; разрешение на проведение было получено ранее от Минздрава ЛатССР. В 2009 г. президент Медведев наградил В. Калнберзса орденом дружбы за достижения в медицине и укрепление отношений двух народов.

Считается, что первая операция (МТF) была проведена в 1931 г. в Германии (по мотивам этой истории в 2015 г. снят фильм «Девушка из Дании» - «The Danish Girl»).

${ }^{14}$ Behavioral Risk Factor Surveillance System (BRFSS) построена на multistate sample, что похоже на кластерную и стратифицированные выборки, см. (Lagos 2018).

${ }^{15}$ Общественная палата России (ОП) заявила об аморальности нахождения на оборотной стороне карты СНИЛС сведений о том, что карта подлежит обмену, в том числе если гражданин сменит пол. Пенсионный фонд России (ПФР) пошел навстречу предложениям ОП. «Однако изменения в тексте на карточке СНИЛС не избавляют от необходимости визита в Пенсионный фонд в случае смены гражданином пола.

Соответствующие документы все же придется представить в ПФР, поскольку пол имеет прямое отношение к возрасту выхода на пенсию», - подчеркивает ПФР. Возраст выхода на пенсию составляет 55 лет для
} 


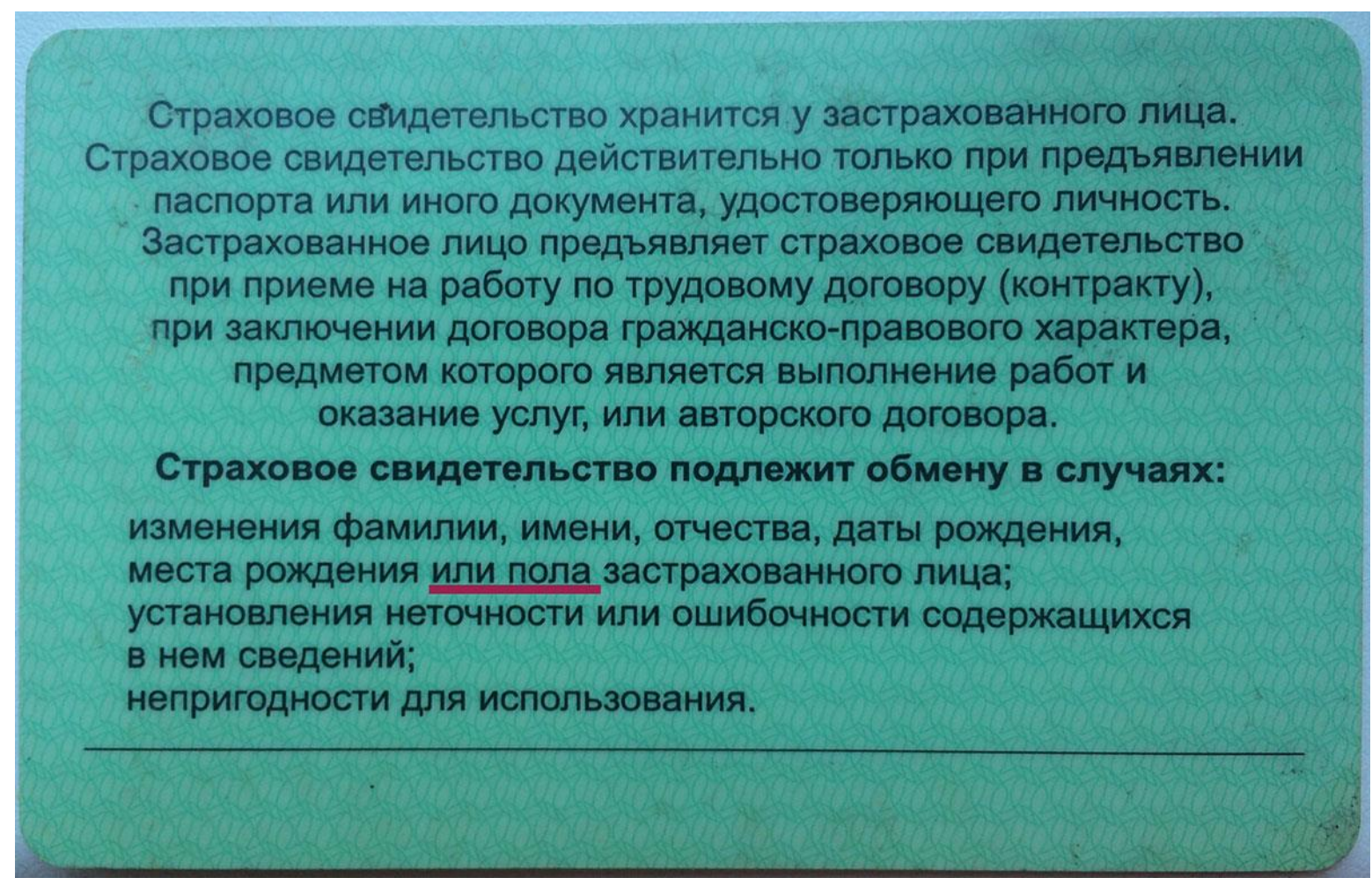

Рисунок 1. СНИЛС

В общих чертах в большинстве случаев гендерный переход выглядит следующим образом: гендерная дисфория > решение сменить пол > гормоны > комиссия (получение разрешения) $>$ операция $>$ решение проблемы. Наше наблюдение сделано в постоперационный период, когда проблемы гендерной дисфории (предположительно должны быть) решены. Предложенная схема работает не во всех случаях, оценить степень её всеобщности трудно и вряд ли возможно на основе собранной на современном этапе информации. Люди находятся в депрессии и отчаянии, ищут и находят самые разные пути.

Гендерная дисфория и, как следствие, жесточайшая депрессия заставляют людей идти по трудному пути смены официального пола. В подавляющем большинстве случаев первым шагом на этом пути является гормонотерапия. Необходимые препараты, несмотря на включение в рецептурные списки ${ }^{16}$, являются доступным и сравнительно недорогим средством изменения гендерного дисплея ${ }^{17}$. Надо отметить тот факт, что даже само начало перехода всегда вызывает значительное улучшение психологического состояния. В связи с тем, что документальная смена пола, а также хирургическая коррекция пола возможны только на основании заключения психиатрической экспертизы, она является неизбежным этапом и условием завершения гендерного перехода. Хирургическая коррекция пола не для

женщин и 60 лет для мужчин. «В связи с этим ПФР призывает женщин, решивших сменить пол, подумать дважды: вам придется выходить на пенсию на пять лет позже», - предостерегает ПФР. Подробнее:

https://www.vestifinance.ru/articles/77821 (дата обращения: 30.01.2019).

${ }^{16}$ Гормонотерапия санкционируется комиссией врачей. Однако аптеки не всегда проверяют рецепты на женские гормоны (хотя они должны отпускаться по рецепту), также доступен черный рынок тестостероновых препаратов и черный рынок рецептов (для примера, забейте в поисковую строку Яндекса «купить рец»). В связи с высокой стоимостью комиссий большинство решивших начать трансгендерный переход начинает гормонотерапию до разрешения комиссии.

17 О гендерном дисплее см. (Здравомыслова, Тёмкина 2015). 
всех приемлема или желаема и в настоящее время является опциональной. Последующие этапы - это смена свидетельства о рождении, включающая в себя смену пола и имени, приведение фамилии и отчества в соответствие с новым документальным полом, а также замена не только старого паспорта, но и всех остальных документов.

Можно предположить, что в результате применённой процедуры в выборке оказались более представлены лица, завершившие гендерный переход, они существенно отличаются от других транс*людей, популяция которых весьма неоднородна. С исследовательской точки зрения среди завершивших гендерный переход чаще наблюдается гетеросексуальные цисгендерные ${ }^{18}$ идентификация и ориентация, которые и являются причинами гендерной дисфории и, соответственно, гендерного перехода ${ }^{19}$. Другой процедурой мог стать выбор из лиц, подающих заявление на гендерный переход и ожидающих разрешения комиссии, но ситуация, в которой они находятся, не располагает к откровенности и общению с посторонними вообще. В планах GDR есть разработка материалов комиссии, из которых можно извлечь скудную, но объективную информацию.

Мы пытались сделать наши результаты подходящими для фальсификации по Попперу (идея Поппера состояла в том, что научный результат может быть фальсифицирован, в более понятном варианте проверен; это требование прозрачности метода и открытия данных при публикации) (Поппер 2005) и сравнимыми с результатами других исследователей, возможно за рубежом. В работе применялись социологические методы исследования, включённое наблюдение и метод экспертных оценок.

Параллельно с телефонным опросом был запущен опрос в сети Интернет, но он пока (начало 2019 г.) не дал ожидаемых результатов, другими словами, число ответов невелико. Этот факт ещё раз свидетельствует о закрытости транс*сообщества и его нежелании выходить из тени.

\section{РезУльтаты}

В первую очередь, гендерный переход отличается по направлению, в нашей выборке оказалось $72 \% \mathrm{mtf}^{20}$ и только $28 \% \mathrm{ftm}$. По возрасту выборка состояла из довольно молодых людей, только 12\% старше 40 лет, по 44\% до и после 25 лет, средний возраст 29,3 $(10,3)^{21}$ года.

Знания респондентов о ВИЧ и СПИД оказались на очень низком уровне (таблица 1), а поражённость этой инфекцией на высоком. Уровень знания о ВИЧ и СПИДе определяли с помощью стандартных вопросов, предлагаемых ЮНЭЙДС (UNAIDS 2017).

\footnotetext{
18 Цисгендер - приставка сіs буквально означает «на этой стороне», так принято называть людей, идентификация и самовыражение которых совпадает с биологическим полом. Вместо термина цисгендерность иногда используют термин гетеронормативность (Исаев 2016).

${ }^{19}$ Например, биологический мужчина чувствует себя женщиной, совершает переход, становится женщиной и продолжает себя чувствовать женщиной, не только придерживаясь гетеросексуальной цисгендерной ориентации и идентификации, но и через секс утверждая своё изменённое я.

${ }^{20} \mathrm{mtf}$ - принятое сокращение, обозначающее переход male to female (от мужчины к женщине), или женщину, которая при рождении была мальчиком; аналогично ftm - female to male.

${ }^{21}$ В скобках - стандартное отклонение.
} 
Пораженность определяли по самоопределению вопросом о знании ВИЧ-статуса (таблица 2). Около половины опрошенных (47\%) оказались ВИЧ-инфицированы.

\section{Таблица 1. Знания респондентов о ВИЧ и СПИДе - абсолютное и относительное распределение ответов}

\begin{tabular}{l|r|r|r|r}
\hline \multirow{2}{*}{ Стандартные вопросы про знание о ВИЧ } & \multicolumn{4}{|c}{ Распределение ответов } \\
\cline { 2 - 5 } & \multicolumn{2}{|c|}{ аболютное } & \multicolumn{2}{c}{ относительное } \\
\cline { 2 - 5 } & да & \multicolumn{1}{c}{ нет } & \multicolumn{1}{c}{ нет } \\
\hline ВИЧ-инфекция и СПИД - одно и то же? & 21 & $\mathbf{2 0 3}$ & 0,094 & 0,906 \\
По внешнему виду человека всегда можно определить, инфицирован ли он & 21 & $\mathbf{2 0 3}$ & 0,094 & 0,906 \\
ВИЧ? & & & \\
Можно ли заразиться ВИЧ при совместном использовании ванны, туалета, & 29 & $\mathbf{1 9 5}$ & 0,129 & 0,871 \\
ббщей посуды или полотенца? & $\mathbf{1 5 9}$ & 65 & 0,710 & 0,290 \\
ВИЧ передается при совместном использовании шприцами и иглами? & 39 & $\mathbf{1 8 5}$ & 0,174 & 0,826 \\
Можно заразиться от укуса комара? & 28 & $\mathbf{1 9 6}$ & 0,125 & 0,875 \\
Передается ли ВИЧ-инфекция при поцелуе? & & &
\end{tabular}

Примечание: Правильные ответы выделены жирным шрифтом.

Таблица 2. Наличие партнёра в момент опроса и знание своего ВИЧ-статуса

\begin{tabular}{l|c|c|r|r}
\hline & \multicolumn{3}{|c|}{ ВИЧ-статус } & \multirow{2}{*}{ Всего } \\
\cline { 2 - 4 } & не знаю & ВИЧ- & ВИЧ+ & \\
\hline Наличие партнера & 29 & 6 & 84 & 119 \\
Отсутствие партнера & 83 & 1 & 21 & 105 \\
Всего & 112 & 7 & 105 & 224 \\
\hline
\end{tabular}

9\% опрошенных полагают, что между ВИЧ и СПИДом разницы нет, что это одно и то же. Можно предположить, что отчасти такое мнение генерируется и СМИ, и специалистами, написание ВИЧ/СПИД встречается очень часто, а разницу между двумя терминами надо объяснять дополнительно. 13\% полагают, что можно заразиться через общие предметы гигиены, 12\% - что ВИЧ передается при поцелуе, а 17\% - что при укусе комара. Последнее, видимо, связано с правильным представлением, что ВИЧ передаётся через кровь, но при этом 29\% респондентов считают, что ВИЧ не передается, если совместно использовать растворы, шприцы и иглы. 9\% респондентов полагают, что могут определить ВИЧ-инфицированного по внешнему виду.

Если суммировать все неверные ответы на базовые вопросы о том, что такое ВИЧ, то получается, что около половины респондентов не знают того или иного факта о ВИЧ или, точнее, имеют неверные знания, что существенно хуже. Всего было задано 6 вопросов, из 224 опрошенных на все 6 вопросов правильно ответили 105 респондентов, на 5 - 72, на 4 - 19, на 3 - 17, на 2 - 7, на 1 - 4. Неправильно ответивших на все вопросы не было.

$12 \%$ респондентов считают, что были инфицированы половым путём. Доли заражения через анальный и вагинальный половой акт оказались примерно равными. Это подчеркивает отличие транс*людей от ключевой группы МСМ (мужчины, имеющие секс с мужчинами). Транс*люди могут быть любой сексуальной ориентации, это следует учитывать при профилактической и другой работе с этой ключевой группой. Мы полагаем, что респонденты были честны в ответах, поскольку соотношение ответов подтверждает наши многолетние наблюдения за транс*сообществом. Парадоксальным образом 44\% инфицированных респондентов считают, что заразились при употреблении общих 
шприцев, игл, растворов и т. п., 38\% инфицированных полагают, что были инфицированы при переливании крови.

Видимо, за переливанием крови как причиной инфицирования стоит рискованное наркопотребление, потому что, если бы столько людей получили ВИЧ в клиниках, это было бы катастрофой, которую трудно скрыть даже при очень небольшой доле этой группы во всём населении. Известно, что по каждому выявленному факту инфицирования в лечебном учреждении Минздрав проводит расследование, выливающееся в грозный приказ. Приказы такого рода являются хорошим дополнительным источником информации об эпидемии. Число их невелико. Подобные приказы, касающиеся переливание крови транс*людям, нам неизвестны. Хотя интервьюер гарантировал анонимность и несмотря на близкий контакт исследователей с сообществом, мы считаем, что респонденты были не всегда искренни при ответе на вопрос о пути передачи или ВИЧ- инфицировании. Вероятно, это связано с привычкой транс*людей скрывать информацию о себе.

Лучшие знания о ВИЧ способствуют решению человека пройти тест (таблица 3).

Таблица 3. Уровень знания о ВИЧ/СПИДе и число тестирований на ВИЧ

\begin{tabular}{l|r|r|r|r|r}
\hline Число правильных ответов на базовые вопросы о ВИЧ & \multicolumn{5}{|c}{ Число тестов на ВИЧ } \\
\cline { 2 - 6 } & нет & 1 & 2 & $2+$ & всего \\
\hline $0-3$ & 7 & 0 & 0 & 0 & 7 \\
$4-5$ & 14 & 4 & 3 & 10 & 31 \\
6 & 8 & 32 & 22 & 19 & 81 \\
Всего & 29 & 36 & 25 & 29 & 119 \\
\hline
\end{tabular}

Таблица 4. Структура источников знаний о ВИЧ/СПИДе, \%

\begin{tabular}{lc}
\hline Источник & Доля указавших \\
\hline Интернет & 33,8 \\
Телевидение & 29,0 \\
Пресса & 13,9 \\
Семья, близкие, знакомые & 13,6 \\
Радио & 7,9 \\
Учебное заведение & 0,9 \\
\hline
\end{tabular}

Примечание: Общеее число ответивщих на вопросы 119.

Самым популярным источником информации о ВИЧ (открытый вопрос; таблица 4) оказался Интернет (34\%), телевизор на втором месте (29\%), на третьем - пресса (14\%), семья и близкие (14\%), другие источники назвали 9\%. Школа и лекции в вузе - менее $1 \%$.

По идее, школа и вузы - те места, где молодые люди (большая часть опрошенных) должны получать достоверную информацию о ВИЧ в первую очередь. Тем не менее они её не получают. В адекватности информации, получаемой через Интернет или СМИ, есть основания сомневаться. Можно констатировать, что государство не справляется с задачей информирования населения, в частности транс*населения, об эпидемии ВИЧ и способах предохранения от заражения. В результате обществу приходится бороться с эпидемией своими силами. Для решения этой задачи общество пользуется различными формами самоорганизации, в частности, создаются НКО, но в начале сентября 2018 г. Минюст 
обнародовал на портале общественной экспертизы поправки к закону ${ }^{22}$ о предупреждении распространения в РФ ВИЧ-инфекции, согласно которым некоммерческие организации обязаны согласовывать свои программы с властями ${ }^{23}$. Критериев, разумеется, нет, и цель правительства не в гармонизации помощи с разных сторон, а в вытеснении не полностью контролируемых им организаций. Таким образом, государство не может решить проблему само и не даёт это делать другим. Если инициатива будет реализована, бороться с ВИЧ солидарно обществу будет ещё труднее, а противостояние ВИЧ станет личным делом.

Как сами респонденты видят решение проблемы с недостаточной информированностью населения? Большинством были названы те же источники (также открытый вопрос), которые были указаны выше, но с большим упором на мероприятия в учебных заведениях, т. е. традиции государственного патернализма очень сильны и первое, что приходит в голову: государство должно... Иными словами, у респондентов есть довольно чёткие представления о том, что должно быть сделано, и сделать это должно государство. Многие молодые люди ответили, что было бы неплохо проводить специальные разъяснительные лекции в учебное время. Возможно, уже заразившись, они понимают, что так могли бы избежать проблем. Меньшая часть сформулировала абсолютно ненаучные, но весьма популярные предложения: изоляция транс*людей от остального общества, привлечение религии и др. Тем не менее эти предложения - свидетельство того, что пропаганда в России с точки зрения борьбы с эпидемией в целом деструктивна, но влияет на умы людей, незначительно, но влияет.

Половина опрошенных знает свой ВИЧ-статус, практически все они инфицированы. Вторая половина не интересовалась своим статусом, но из этого не следует, что эти люди не инфицированы ВИЧ, хотя с учётом специфики группы (отсутствие контакта с медициной), скорее всего, нет. Нельзя сказать, что они не попадали в ситуацию, когда тестирования не избежать, любое попадание в клинику для вмешательства в нашей стране сопровождается ВИЧ-тестом (Denisov 2006; Денисов, Сакевич 2004).

Более 2/3 инфицированных опрошенных принимают терапию, соответственно 1/3 к ней не прибегает. Причины отказа от терапии специально не изучались, тем не менее, это означает, что эти люди не могут или не хотят получать терапию. Каждый третий не скажет своему партнеру о своем диагнозе (в случае инфицирования), что может повлечь за собой серьёзные последствия. При устойчивости пары вероятность передачи инфекции велика, что может рассматриваться как умышленное заражение заболеваниями, передаваемыми половым путем (ЗППП).

\section{ЗАКЛЮЧЕНИЕ}

Профилактика ВИЧ на государственном уровне работает плохо, а среди российского транс* населения её практически нет. Поражённость группы очень велика ${ }^{24}$. Обследованное

\footnotetext{
${ }^{22}$ URL: https://www.interfax.ru/russia/627798 (дата обращения: 30.01.2019).

${ }^{23}$ URL: https://www.interfax.ru/russia/627980 (дата обращения: 30.01.2019).

${ }^{24}$ Настолько велика, что вызывает сомнения в адекватности полученного результата. 
население плохо информировано о ВИЧ, значительной доле транс*людей безразлично, есть ли у них ВИЧ или нет. Представления о путях передачи ВИЧ совершенно неадекватны. Знание статуса, скорее всего, связано с повышенной частотой обращений за специальным лечением (предполагающим ВИЧ-тест) сравнительно с остальным населением. Подтвердилось мнение, что транс*люди - это очень замкнутая группа, не стремящаяся идти на контакт из-за общих трансфобии и неприятия в обществе. Они не только изолированы, но и часто не имеют средств к существованию, что является одной из причин обращения к коммерческому сексу в качестве заработка, и достучаться до них со стороны, а тем более объяснить суть профилактики ВИЧ, очень тяжело. Поэтому проблемами транс* населения должны заниматься организации, которые специализируются именно на таких людях. Для начала можно попытаться ввести их в общую систему здравоохранения, чтобы транс*люди не боялись ходить к врачам и обращаться за бесплатной помощью. Для этого потребуется избавиться от стигматизации и дискриминации в больницах и поликлиниках. Это непросто, но надо понимать, что трансгендеры никуда не исчезнут, даже если делать вид, что их не существует.

Авторы понимают, что их выборка мала и неслучайна, распространять полученные результаты на всё транс*население вряд ли возможно. Основная задача была в привлечении внимания к проблеме относительно новой ключевой группы и попытке вывести её из тени на свет общественного обсуждения.

\section{ЛИТЕРАТУРА}

ВИЧ-инфекция (2018). Федеральный научно-методический центр по профилактике и борьбе со СПИДом. Информаџионный бюллетень, 42.

Демедецкая Я., Денисов Б., Сакевич В. (2017). Трудности формирования семей трансгендерами (на примере выборочного исследования). Успехи современной науки, 9(4), 218-224.

Денисов Б., Сакевич В. (2004). Динамика эпидемии ВИЧ/СПИД. Социологические исследования, 1, 75-85.

Здравомыслова Е., Тёмкина А. (2015). 12 лекций по гендерной сочииологии. СПб.

Исаев Д.Д. (2016). Деконструкция гетеронормативной матрицы. Психология, 13(1), 9-26.

Менделевич В.Д. (2018). О многодетной матери Юлии Савиновских, лишённой детей изза желания сменить пол (трагические юридические последствия несовершенства психиатрических классификаций). Неврологический вестник, 1, 5-14.

Поппер К. (2005). Логика научного исследования. М.: Республика.

Русанова Н.Е. (2008). Репродуктивные возможности демографического развития. М.

Byrne J. (2014). License to Be Yourself. New York.

Denisov B. (2006, June). The Russian HIV/AIDS Case Reporting System. Paper presented at the European Population Conference, Liverpool, United Kingdom (Session 303, HIV/AIDS).

Lagos D. (2018). Looking at population health beyond "male" and "female": implications of transgender identity and gender nonconformity for population health. Demography, 55(6), 2097-2117. 
Keegan C.M. (2018). Getting Disciplined: What's Trans* About Queer Studies Now? Journal of homosexuality, 1-14.

UNAIDS (2017). Global AIDS Monitoring 2018 Indicators for monitoring the 2016 United Nations Political Declaration on Ending AIDS.

Nicolazzo Z. (2016). 'It'sa hard line to walk': Black non-binary trans* collegians' perspectives on passing, realness, and trans*-normativity. International Journal of Qualitative Studies in Education, 29(9), 1173-1188. 


\title{
HIV IN TRANS*POPULATION: LOCAL CASE STUDY
}

\author{
YAEL DEMEDETSKAYA, BORIS DENISOV, ALISA LAPITSKAYA
}

\begin{abstract}
The article presents the results of a sample survey of 224 trans* people carried out in 2017 by the Gender Dynamics Research (GDR) group. The survey revealed a very high degree of HIV prevalence of the group. In addition, the survey revealed a very low level of knowledge and awareness of HIV infection and methods of its spread in the population. Sources of knowledge about HIV are more or less standard. Attitudes toward the fact of infection and possible infection can be characterized as indifferent or inadequate, which is likely determined by severe stigmatization of the group and a high level of discrimination experienced by it. The state is not coping with the spread of HIV infection.
\end{abstract}

Key words: trans*, transgender, LGBT, HIV/AIDS, HIV infection, sample survey.

YAEL DEMEDETSKaya (yaelkroy@gmail.com), TrAnsgender Foundation, Russia.

Boris Denisov (denisov@demography.ru), GENDER DyNAMICs RESEARCH, RusSIA.

Alisa LaPITSKaya (lapitskaya.alisa@gmail.com), Gender Dynamics Research, Russia.

DATE RECEIVED : FEBRUARY 2019.

\section{REFERENCES}

Byrne J. (2014). License to Be Yourself. New York.

Demedetskaya YA., Denisov B., Sakevich V. (2017). Trudnosti formirovaniya semey transgenderami (na primere vyborochnogo issledovaniya) [Difficulties in the formation of families by transgenders (through the example of a sample study)]. Modern Science Success, 9(4), 218-224 (In Russ.).

Denisov B. (2006, June). The Russian HIV/AIDS Case Reporting System. Paper presented at the European Population Conference, Liverpool, United Kingdom (Session 303, HIV/AIDS).

Denisov B., Sakevich V. (2004). Dinamika epidemii VICH/SPID (The dynamics of the HIV / AIDS epidemic). Sociological Studies, 1, 75-85 (In Russ.).

Isayev D.D. (2016). Deconstruction of heteronormative matrix. Psychology 13(1), 9-26 (In Russ.).

Keegan C.M. (2018). Getting Disciplined: What's Trans* About Queer Studies Now? Journal of homosexuality, 1-14.

Lagos D. (2018). Looking at population health beyond "male" and "female": implications of transgender identity and gender nonconformity for population health. Demography, 55(6), 2097-2117.

Mendelevich V.D. (2018). O mnogodetnoy materi Yulii Savinovsikh, lishënnoy detey iz-za zhelaniya smenit' pol (Tragicheskiye yuridicheskiye posledstviya nesovershenstva psikhiatricheskikh klassifikatsiy). [About the mother of a large family, Yulia Savinovsikh, deprived of children because of the desire to gender reassignment (the tragic legal consequences of the imperfection of psychiatric classifications)]. Neurological Bulletin 1, 514 (In Russ.). 
Nicolazzo Z. (2016). 'It's a hard line to walk': Black non-binary trans* collegians' perspectives on passing, realness, and trans*-normativity. International Journal of Qualitative Studies in Education, 29(9), 1173-1188.

Popper K. (2005). Logika nauchnogo issledovaniya. [The Logic of Scientific Discovery]. Moscow: Respublika (In Russ.).

Rusanova N.E. (2008). Reproduktivnyye vozmozhnosti demograficheskogo razvitiya. [Reproductive opportunities of demographic development]. Moscow (In Russ.).

UNAIDS (2017). Global AIDS Monitoring 2018 Indicators for monitoring the 2016 United Nations Political Declaration on Ending AIDS.

VICH-infektsiya [HIV infection] (2018). Federal'nyy nauchno-metodicheskiy tsentr po profilaktike i bor'be so SPIDom [Federal Scientific and Methodological Center for the Prevention and Control of AIDS]. Informatsionnyy byulleten [Information bulletin], 42 (In Russ.).

Zdravomyslova Ye., Tomkina A. (2015). 12 lektsiy po gendernoy sotsiologii [12 lectures on gender sociology]. Saint-Petersburg (In Russ.). 